Research Article

\title{
Compression Characteristics and Constitutive Model of Low-Exotherm Modified Polyurethane Grouting Materials
}

\author{
Shengjie Xu $\mathbb{D}^{1},{ }^{1}$ Shuangjie Wang, ${ }^{2}$ Yanhui Zhong $\mathbb{D},{ }^{1}$ Bei Zhang $\mathbb{D}^{1},{ }^{1}$ Juan Zhang, \\ Yanjun Wang, ${ }^{3}$ and Liguo Zhao ${ }^{2}$ \\ ${ }^{1}$ College of Water Conservancy and Engineering, Zhengzhou University, Zhengzhou 450001, China \\ ${ }^{2}$ CCCC First Highway Consultants Co., Ltd., Beijing, China \\ ${ }^{3}$ Jilin Communication Planning and Designing Institute, Jilin, China
}

Correspondence should be addressed to Yanhui Zhong; zhong_yanhui@163.com and Bei Zhang; beizhang@126.com

Received 23 October 2019; Revised 13 October 2020; Accepted 14 October 2020; Published 9 November 2020

Academic Editor: Pitthaya Jamsawang

Copyright (c) 2020 Shengjie Xu et al. This is an open access article distributed under the Creative Commons Attribution License, which permits unrestricted use, distribution, and reproduction in any medium, provided the original work is properly cited.

In permafrost regions, ordinary polyurethane grouting materials are not suitable for the repair and reinforcement of road engineering due to the release of a large amount of heat during the reaction process. In this study, the polyurethane grouting material is modified by changing the catalyst, blowing agent, and reaction scheme to reduce the heat released during the reaction. The stress-strain curves of low-exotherm polyurethane grouting material specimens possessing various densities are investigated by means of unconfined uniaxial compression experiments, and the stress-strain relationships and failure mode of low- and highdensity specimens are analysed. The characteristics of three stages in the compression process of the materials, namely, the elasticity stage, platform stage, and densification stage, are studied. The compressive strength increases with the increase in density, and the brittle failure of materials with higher density is more obvious. From the microscopic point of view, combined with the experimental results, the constitutive model of low-exotherm modified polyurethane grouting material was established. The established model is in good agreement with the experimentally measured stress-strain curves and effectively predicted the stress-strain characteristics for a specimen possessing a different density.

\section{Introduction}

Frozen soil is a special kind of soil. Due to the existence of ice, frozen soil is greatly affected by temperature changes. A series of mechanical behaviour changes occur in the frozen soil due to temperature changes, resulting in uneven frost, thawing, and pumping of the subgrade. Throughout the history of road engineering in permafrost regions, the reinforcement and restoration of road works is extremely difficult. As a kind of repairing material, grouting material is widely used in the repair and reinforcement of pavements, bridges, dams, and buildings due to its strong cohesiveness, easy operation, and strong permeability. Over the past few decades, a variety of grouting materials have been developed, including water glass, silica sol, cement, polyurethane, and epoxy, depending on the purpose and local conditions [1]. The widely used polyurethane grouting material can effectively repair different diseases of road engineering. After the two prepolymers are injected into the place of void position or settlement through a grouting tube, the mixed prepolymers will react and expand quickly to form polymer and deal with the distresses of void or settlement. Polyurethane grouting materials have excellent comprehensive properties, including good chemical stability, large expansion force, high strength, long durability, low permeability, and fast reaction speed [2]. However, ordinary polyurethane grouting materials release a large amount of heat during the reaction process, which is not suitable for the repair and reinforcement of road engineering in permafrost regions. Therefore, it is urgent to study the low-exotherm modified polyurethane grouting materials suitable for use in permafrost regions.

For polyurethane grouting materials, a large number of studies have been carried out in the laboratory, including 
compression characteristics [3-8], tensile properties [9-12], fatigue properties $[2,13,14]$, shear characteristics [15], and impermeability characteristics $[16,17]$. Bezazi et al. presented a comparative analysis between the cyclic loading compressive behaviour of conventional, isodensity nonauxetic, and auxetic (negative Poisson's ratio) polyurethane material [14]. The microstructure evolution of polyurethane grouting material and fatigue damage parameters to characterize the evolution of material modulus, under cyclic compressive loading, was analysed by Gao et al. $[4,13]$. The polyurethane grouting materials were analysed with particle flow code in the two-dimensional method (PFC2D), using conventional triaxial tests, to quantitatively evaluate the damage behaviour of polymer materials by Heng et al. [2]. The uniaxial compression test at quasistatic and dynamic loading rates was studied to observe the impact response of rigid polyurethane foam at different rates by Mane et al. [4]. It was discovered that the peak stress is strain rate sensitive and depends on the square of the foam density by Chen et al. [5]. The tensile response of polyurethane materials was studied by Fan and Nie, including the effects of strain rate and cyclic load $[9,10]$. Nonlinear behaviour of foams under static and impact three-point bending was investigated by Marsavina et al. [18]. In addition, Anna Andersson investigated the shear properties of the material [15]. For the study of the mechanical model of materials, a thermodynamic constitutive model was proposed by Hisaaki et al. [19]. Wronski et al. introduced a new hypoplastic model that can be easily identified [20]. A semiempirical model of materials based on the Gibson-Ashby model was established by Gao [3].

In recent years, various modified polyurethane materials had been developed for different application ways. It was found that the catalyst had a great influence on the polyurethane grouting material by Zhang et al. A small amount of catalyst can improve the reaction speed and early strength of the polyurethane grouting material [21]. Adding nanosilica to polyurethane grouting material can improve the toughness of materials and enhance the mechanical properties of high temperature and low temperature [22]. The reaction product (polyurethane material), with high impact resistance and toughness, of a modified MDI isocyanate and a sucrose/glycerine-based polyether polyol resin catalysed by a mixture of one or more tertiary amines and water was investigated by Leroy et al. [23].

In this study, the polyurethane grouting material is modified by changing the catalyst, blowing agent, and reaction scheme to reduce the heat released during the reaction. The uniaxial compression test is carried out on the low-exotherm modified polyurethane grouting material, and the test results are analysed. The constitutive model of the material is analysed from a microscopic perspective.

\section{Low-Exothermic Modification Scheme}

The main raw materials used in the preparation of polyurethane grouting materials are polyols, polyisocyanates, blowing agents, catalysts, and various other auxiliaries. The reaction mainly includes a gel reaction and a foaming reaction. Both reactions are exothermic reactions in which the exotherm of the isocyanate and water is the highest ( $45 \mathrm{cal} / \mathrm{mol}$ ), followed by the gelation of the isocyanate with the polyol $(24 \mathrm{cal} / \mathrm{mol})$.

Since the foaming reaction of isocyanate with water will produce a lot of heat quantity, the reaction temperature is gradually increased as the moisture content increases (as shown in Figure 1), so the amount of water in the formulation must be reduced. In order to ensure the quality and density of the polyurethane foam, it is necessary to add an appropriate amount of physical foaming agent. The physical foaming agent is a kind of low boiling point compound, which can absorb heat and vaporize during the formation of the foam. Since the physical foaming agent has the characteristic of heat absorption, the increase in the content thereof is beneficial to lower the maximum reaction temperature. HCFC-141 b (1, 1-dichloro-1-fluoroethane) is the most suitable physical foaming agent found by our experiments (as shown in Figure 2). At the same time, a high boiling point solvent is added to the formulation to absorb some of the heat.

In order to further reduce the reaction temperature and ensure the excellent properties of polyurethane materials, part of the heat is generated in the reaction and prepolymer is formed. The part of the isocyanate is replaced by a prepolymer, which not only effectively reduces the heat of the reaction but also greatly improves the material properties.

\section{Compression Experiment of Low-Exotherm Modified Polyurethane Grouting Materials}

3.1. Specimen Fabrication and Compression Experiment. The low-exotherm modified polyurethane grouting materials are composed of isocyanate and polyether polyol as the two main components in addition to a catalyst and foaming agent as auxiliary agents. Cylinders are used as the experimental specimens with a diameter of $50 \mathrm{~mm}$ and a height of $100 \mathrm{~mm}$. The forming mould (we use rigid moulds to represent the field environment approximately) is composed of a seamless steel pipe with a length of $600 \mathrm{~mm}$, an inner diameter of $50 \mathrm{~mm}$, and a wall thickness of $10 \mathrm{~mm}$ which is cut into two symmetrical halves in the radial direction and two covers with a grouting hole and an exhaust hole (both of which have diameters of $10 \mathrm{~mm}$ ) as depicted in Figure 3.

The reactants are mixed using grouting equipment and injected into the mould at a particular grouting pressure (7 $\mathrm{MPa})$. Upon reaction, the reactants rapidly expanded and solidified in the mould. Each moulded specimen is allowed to cool for $1 \mathrm{~h}$, the mould bolts and covers are removed, and the formed cylindrical specimen is extracted and precisely cut into $100 \mathrm{~mm}$ long, $50 \mathrm{~mm}$ diameter cylindrical specimens using a lathe. As the volume of the moulding die is fixed, the specimen density can be varied by changing the amount of grouting material injected. The processed specimens are divided into three groups according to their density, namely, $0.08-0.2,0.2-0.3$, and $0.3-0.4 \mathrm{~g} / \mathrm{cm}^{3}$ (specimens with the density of $0.1 \mathrm{~g} / \mathrm{cm}^{3}$ can be obtained by injecting $117.9 \mathrm{~g}$ grouting materials). It is more convenient to analyse the effect of density on mechanical properties by 


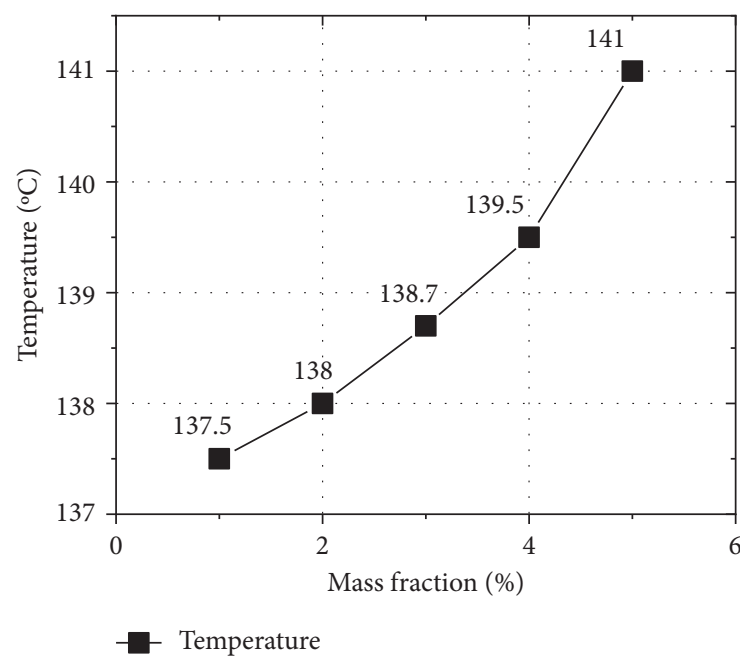

FIGURE 1: Water effect on temperature.

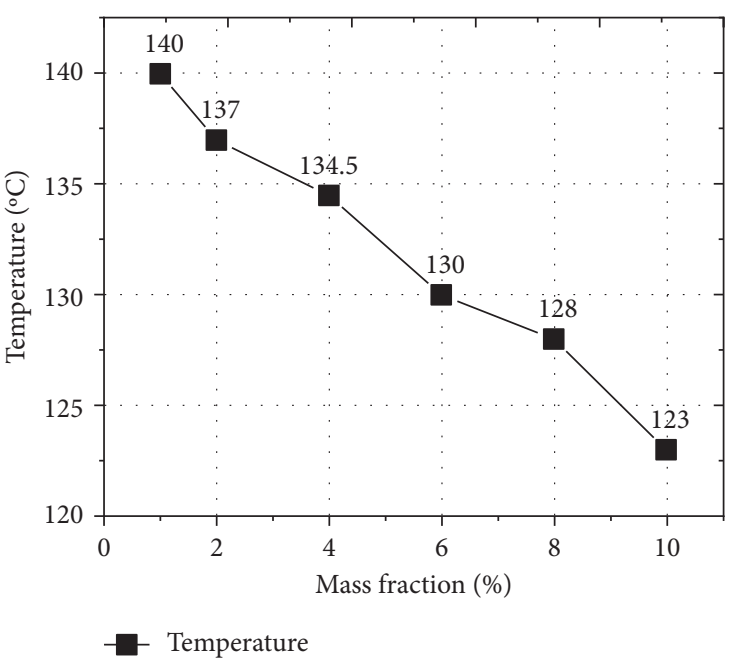

Figure 2: HCFC-141 b effect on temperature.

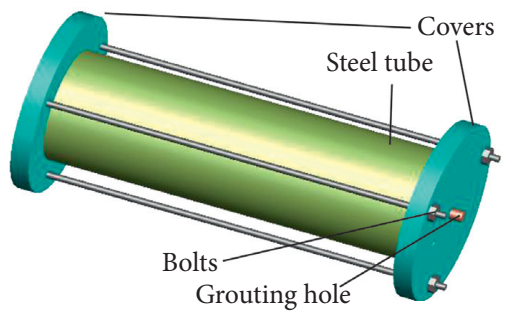

Figure 3: Specimen mould.

dividing three groups of specimens. There are four or three specimens (same mould and same density range) in each group, and the shaped specimens are shown in Figure 4.

The specimens are tested using an electronic universal tensile testing machine, which has an accuracy of $0.05 \%$ and a maximum load of $50 \mathrm{kN}$. Displacement control is used in the experiments, and the loading rate is $2 \mathrm{~mm} / \mathrm{min}$. The loading and displacement are recorded during the entire

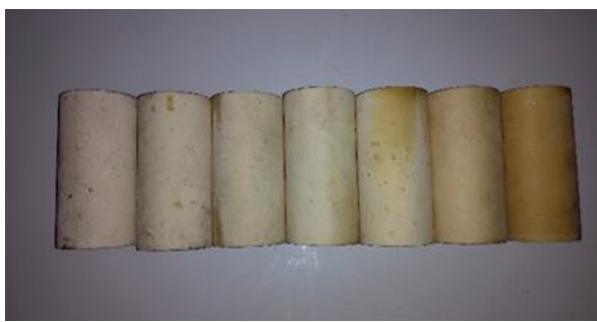

Figure 4: Test specimens.

process and subsequently analysed. The experiment is manually terminated either when the deformation reached 0.8 , providing the deformation response of the material during the entire compression process, or when the stress decreased suddenly, indicating the failure of the specimen.

The axial strain $\varepsilon$ of a low-exotherm modified polyurethane grouting material specimen can be expressed as follows:

$$
\varepsilon=\frac{\Delta h}{H},
$$

where $\Delta h$ and $H$ are the axial deformation and initial length, respectively, of the specimen.

The axial stress $\sigma$ of a low-exotherm modified polyurethane grouting material specimen can be expressed as

$$
\sigma=\frac{P}{A}
$$

where $P$ is the pressure load and $A$ is the cross-sectional area of the specimen.

3.2. Viscosity Test of Polyurethane Grouting Materials. The viscosity of polyurethane grouting materials and the viscosity during the reaction were measured by using the SNB-2 viscometer (as shown in Figure 5 and Table 1).

At the initial stage of reaction, the viscosity of grouting material is stable at $0.52 \mathrm{~Pa} \cdot \mathrm{s}$. When the reaction takes 60 seconds, the viscosity increases rapidly. Finally, a stable rigid polyurethane foam is formed.

3.3. Stress-Strain Curves and Failure Mode. In unconfined compression experiments, the response of the specimen generally includes three stages. The first stage is the linear elasticity stage, where the strain is less than 0.05 , during which the cell of the specimen uniformly deforms under the pressure, the cell edge bears the main load, and the cell deformation is recoverable. When the strain exceeds 0.05 , the specimen undergoes a transition from elastic deformation to plastic deformation, whereupon the cell of the specimen ruptures and collapses, the strain increases continuously, and the stress increases slowly or remains essentially unchanged. This second stage is the platform stage. The stress in the platform stage can be used to characterize the compressive strength (compressive strength of different densities is shown in Figure 6). As the strain continues to gradually increase, the cell is almost completely destroyed and the specimen enters the densification stage, at which the 


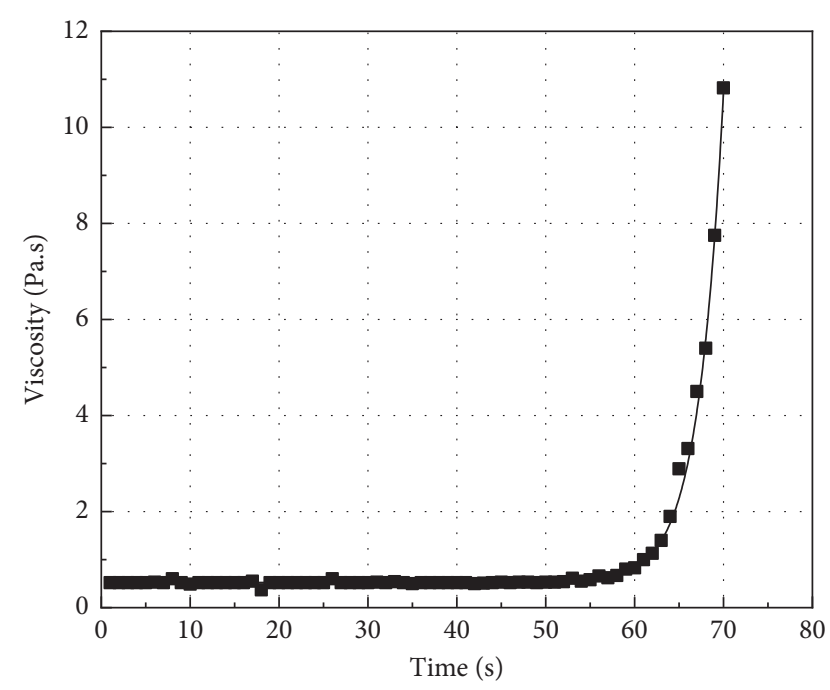

FIgURE 5: Viscosity change during the reaction.

TABLE 1: Viscosity of materials.

\begin{tabular}{lc}
\hline Material & Viscosity $(\mathrm{Pa} \cdot \mathrm{s})$ \\
\hline Isocyanate & 0.483 \\
Polyether polyol & 0.192 \\
\hline
\end{tabular}

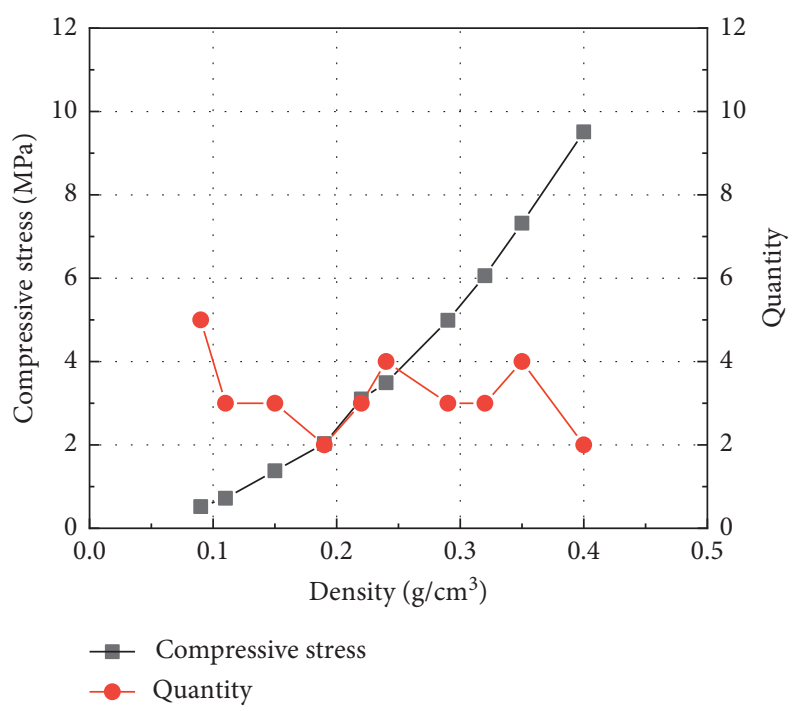

Figure 6: Compressive strength of different densities.

strain is between 0.4 and 0.5 . The inflection point strain decreases with increasing density. The stress in the densification stage increases significantly with increasing strain, and the slope is close to the elasticity modulus of the matrix. The stress-strain curves of specimens possessing various densities are presented in Figure 7, and the mechanical parameters are listed in Table 2.

The low-density specimens $\left(\rho<0.2 \mathrm{~g} / \mathrm{cm}^{3}\right)$ displayed no macroscopic cracks during the entire process, and the partial deformation recovered slowly after unloading. In contrast, the high-density specimens $\left(\rho \geq 0.2 \mathrm{~g} / \mathrm{cm}^{3}\right)$ exhibited obvious brittle failure characteristics, displaying longitudinal

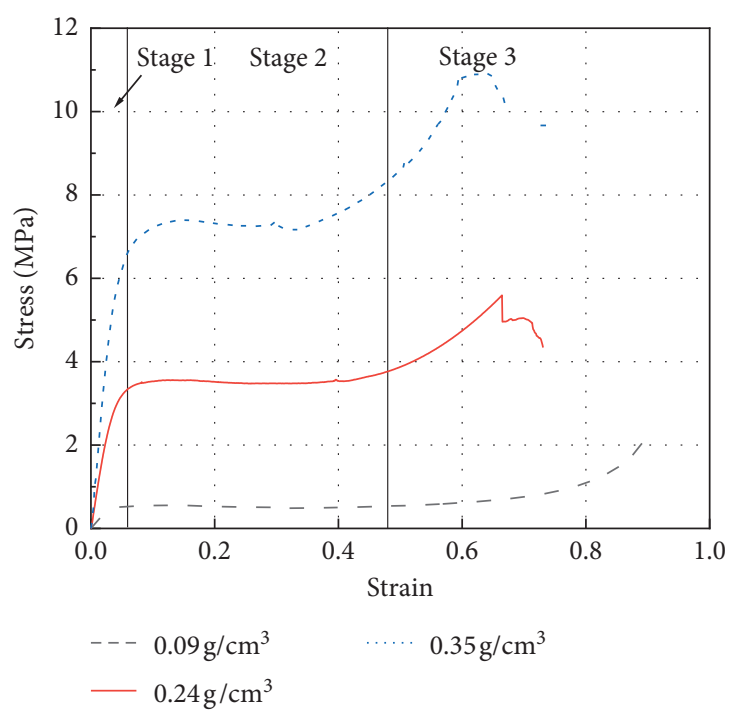

FIGURE 7: Stress-strain curves.

TABle 2: Mechanical parameters of specimens with different densities.

\begin{tabular}{lcc}
\hline Density $\left(\mathrm{g} / \mathrm{cm}^{3}\right)$ & Elasticity moduli $(\mathrm{MPa})$ & Yield strengths $(\mathrm{MPa})$ \\
\hline 0.09 & 17.65 & 0.52 \\
0.24 & 89.73 & 3.49 \\
0.35 & 175.95 & 7.34 \\
\hline
\end{tabular}

cracks when the strain reached approximately 0.65 . The loading patterns for the specimens possessing various densities are shown in Figures 8 and 9. The compressive strength of the specimens increased with increasing density.

3.4. Microscopic Characteristics of Polyurethane Grouting Materials. SEM (KYKY-EM600) images of microstructure and morphology of the polyurethane grouting materials are shown in Figures 10 and 11. It can be seen that the polyurethane grouting materials are composed of closed cells. The shape of low-density cell is between spherical and polygonal, with a large contact area. In contrast, the shape of high-density cell is mainly spherical and ellipsoidal, with a small contact area, which means that the free space between the cells is larger.

These phenomena can be explained by the minimum energy principle. The results show that the shape of the highdensity cell is spherical with the minimum specific surface area, and the distance between the cells is far, so the total surface energy of the system is the lowest and the system is the most stable. In contrast, the gas volume of the low-density cell, with small free space, is large. The shape changes from spherical to polygonal and loses the spherical characteristics.

\section{Constitutive Model of Low-Exotherm Modified Polyurethane Grouting Materials}

The low-exotherm modified polyurethane grouting materials are a type of closed-cell foam material (a single closed cell is shown in Figure 12). Data regarding the matrix material, cell characteristics, and foam material 


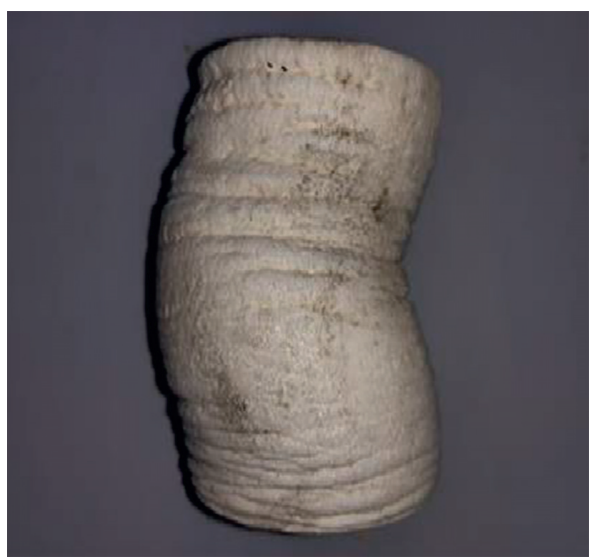

FIGURE 8: Failure response of low density.

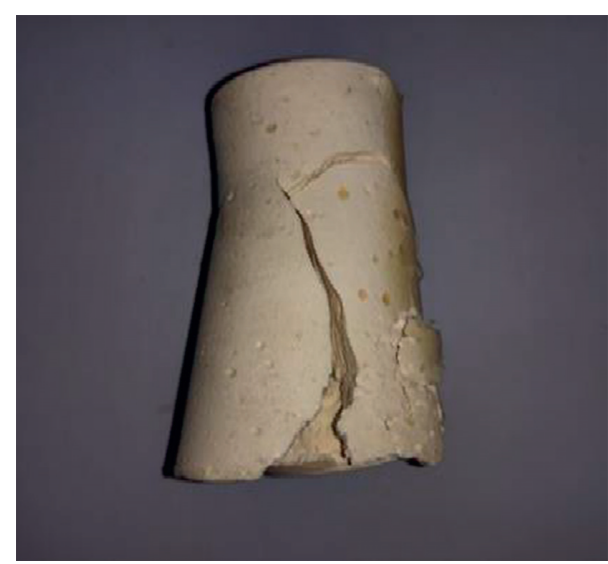

FIGURE 9: Failure response of high density.

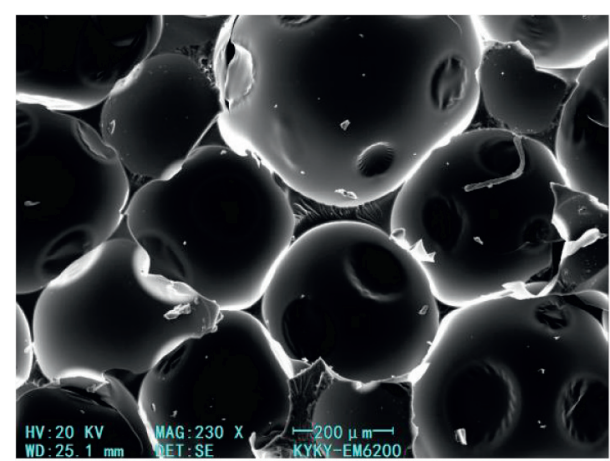

Figure 10: Microscopic characteristics of low density.

properties are generally required for the comprehensive analysis and modeling of complex closed-cell foams [24].

On the basis of the experimental results described in the previous section, the compressive mechanical properties of the lowexotherm modified polyurethane grouting materials belong to the elastoplastic regime. The response of the specimen can be divided into three stages, namely, the linear elasticity stage, platform stage, and densification stage. According to the study of the deformation mechanism, the first stage mainly involves the joint effects of cell wall tension and bending. The second stage is the platform stage, during which the cell begins to bend and collapse and cannot be

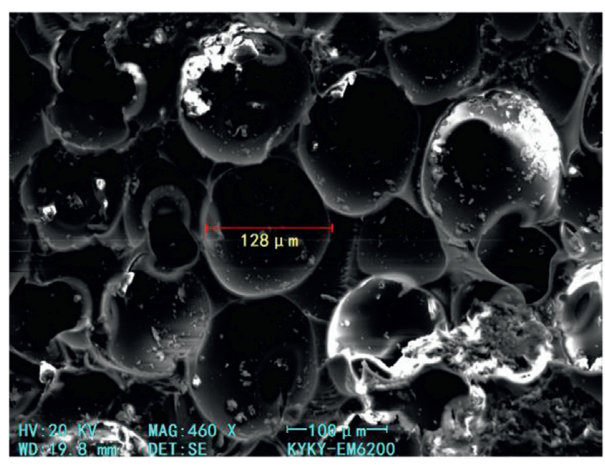

Figure 11: Microscopic characteristics of high density.

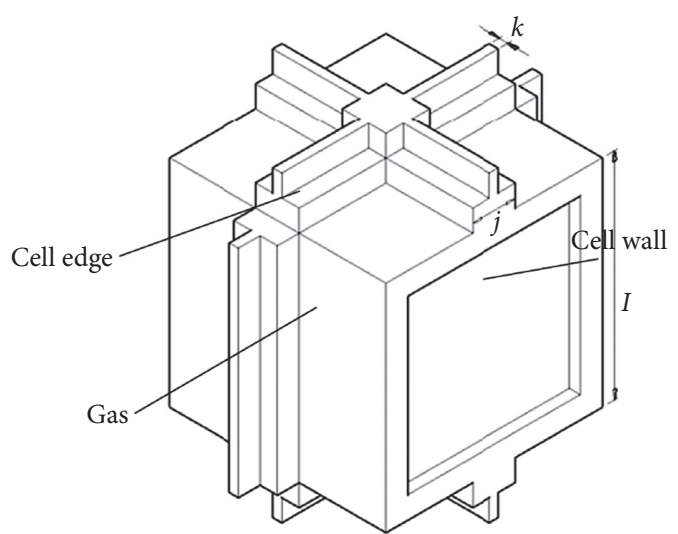

FIgURE 12: A single closed cell.

restored to its original state after unloading. The third stage is the densification stage, during which the cell collapses completely and further compression compresses the matrix material. The stressstrain curves of low-exotherm modified polyurethane grouting materials can therefore be simplified using these three stages, where the linear elasticity, platform, and densification stages correspond to an oblique line, horizontal line, and rapid increase, respectively.

4.1. Linear Elasticity Stage of Constitutive Model. Grouting materials are a kind of closed-cell material, the stiffness of which mainly originates from the bending of the cell edge in the direction of compression.

$$
E=E_{j}+E_{k}+E_{\text {gas }},
$$

where $E, E_{j}, E_{k}$, and $E_{\text {gas }}$ are the elasticity moduli of the foam material, cell edge, cell wall, and gas, respectively, and $v$ is Poisson's ratio.

When the cell produces longitudinal compression, according to the principle of conservation of energy, we can get the following results.

For gas,

$$
\begin{aligned}
V_{1} & =\left(1-\varepsilon_{x}+\varepsilon_{y}+\varepsilon_{z}\right) V_{0}, \\
V_{\text {gas } 1} & =\frac{1-\varepsilon_{z}(1-2 v)-\left(\rho / \rho^{\prime}\right)}{1-\left(\rho / \rho^{\prime}\right)} V_{\text {gas } 0},
\end{aligned}
$$




$$
E_{\mathrm{gas}}=\frac{\mathrm{d} P}{\mathrm{~d} \varepsilon_{z}}=\frac{(1-2 v)}{1-\left(\rho / \rho^{\prime}\right)} P,
$$

where $V_{0}$ and $V_{1}$ are cell volume before compression and cell volume after compression, respectively; $V_{\text {gas } 0}$ and $V_{\text {gas } 1}$ are gas volume before compression and gas volume after compression, respectively; $\rho$ and $\rho^{\prime}$ are the density of the foam material and matrix material, respectively; $P$ is atmospheric pressure.

For cell edge and wall,

$$
\begin{aligned}
F l \varepsilon_{z} & =\alpha \frac{I E^{\prime} \varepsilon_{z}^{2}}{l}+\beta^{\prime \nu^{2} E^{\prime} \varepsilon_{z}^{2}} k l^{2}, \\
E_{j}+E_{k} & =\left(\alpha \frac{j^{4}}{12 l^{4}}+\beta \frac{k}{l}\right) E^{\prime}, \\
\frac{k}{l} \infty \frac{(1-\varphi) \rho}{\rho^{\prime}} & \\
E_{j}+E_{k} & =\left(\alpha\left(\frac{\varphi \rho}{\rho}\right)^{\xi}+\beta \frac{(1-\varphi) \rho}{\rho^{\prime}}\right) E^{\prime},
\end{aligned}
$$

where $E$ and $E^{\prime}$ are the elasticity moduli of the foam material and matrix material, respectively; $\varphi$ is the mass fraction of the cell edge; $\alpha$ and $\xi$ are empirical coefficients representing the shape complexity and size ratio of all cells, where $\xi=2 ; \beta$ is an empirical coefficient representing the influence of membrane stress.

The mass fraction of the cell edge can be calculated using the following equation [3]:

$$
\begin{gathered}
\varphi=1-\frac{1}{2}\left(\frac{\rho^{\prime}}{\rho}-1\right) j \omega, \\
\varphi=1-\frac{\rho^{\prime} d k}{2 \cdot\left(1-\rho^{\prime}\right)},
\end{gathered}
$$

where $\omega$ is the specific surface area; $\rho^{\prime}$ is the porosity of the material; $k$ is the ratio of cell area to cell volume [6].

During the stage of compression, the membrane stress caused by the curvature of the cell edge and the stress caused by the compression of gas or liquid in the cell also exert a certain influence on the elasticity modulus of the material. The elasticity modulus of a gas-containing closed cell with membrane stress can be determined using the following equation [24]:

$$
\frac{E}{E^{\prime}}=\alpha\left(\varphi \frac{\rho}{\rho^{\prime}}\right)^{\xi}+\beta(1-\varphi) \frac{\rho}{\rho^{\prime}}+\frac{P(1-2 v) \rho_{d}}{E^{\prime}\left(\rho^{\prime}-\rho\right)} .
$$

Gibson and Ashby reported general reference values for the empirical coefficients in this equation: $\alpha \approx \beta \approx 1$ and $v=(1 / 3)$. The third term (the stress caused by the compression of gas or liquid) can be neglected owing to the small amount of intracellular gas.
For the low-exotherm polyurethane grouting materials, the following values are adopted in the calculations after correction of experimental data:

$$
\alpha \approx \beta \approx 2.38\left(\frac{\rho}{\rho^{\prime}}\right)^{0.5} .
$$

4.2. Platform Stage of Constitutive Model. The experimental results for the low-exotherm polyurethane grouting materials demonstrate that the linear elasticity stage occurred under small strain ( $5 \%$ or less), whereas the strain range of the platform stage during which the stress remained essentially unchanged is very large. This value of the stress during the platform stage is referred to as the platform stress $\sigma_{t}$ or plastic collapse stress.

At a platform stage, the collapse of the cell can be considered as a plastic hinge structure formed at the edge of the cell apex, which is related to the yield strength $\sigma_{\mathrm{ds}}$ of the matrix material, and the influence of the membrane stress on the cell wall is also considered. $\sigma_{\mathrm{d} s}$ can be represented by the following equation:

$$
\begin{aligned}
F \varepsilon_{z} l & =\eta \sigma_{p}^{\prime} W_{j} \theta_{j}+\xi \sigma_{p}^{\prime} \varepsilon_{k} V_{k}, \\
\sigma_{p} A_{\text {cell }} \varepsilon_{z} l & =\eta \sigma_{p}^{\prime} W_{j} \theta_{j}+\xi \sigma_{p}^{\prime} \varepsilon_{k} V_{k}, \\
\frac{\sigma_{t}}{\sigma_{\mathrm{d} s}} & =\gamma\left(\varphi \frac{\rho}{\rho^{\prime}}\right)^{1.5}+\eta(1-\varphi)\left(\frac{\rho}{\rho^{\prime}}\right),
\end{aligned}
$$

where $W_{j}$ is the polar moment of inertia of cell edge, $\theta_{j}$ is the rotation angle of cell edge, and $\gamma$ and $\eta$ are empirical constants representing the shape complexity and size ratio of all cells.

After correction of experimental data, the following values are adopted in the calculations:

$$
\gamma \approx \eta \approx 0.97\left(\frac{\rho}{\rho^{\prime}}\right)^{0.75}
$$

4.3. Densification Stage of Constitutive Model. When the strain reached more than 0.4-0.5 (this value decreases with the increase in density), the material entered the densification stage, during which the cell of the material is essentially destroyed. The cell walls contact each other, and the stress increases with the strain. At a later stage of compression, the stiffness of the material originates from the base material itself such that the slope of the rising stress-strain curve ultimately approaches $E_{s}$. The inflection point strain $\varepsilon^{\prime}$ between the platform and densification stages decreases with increasing density. Based on the correction of experimental data, $\varepsilon^{\prime}$ can be expressed as follows:

$$
\left(1-\varepsilon^{\prime}\right)^{k}=\frac{4}{3} \rho^{-0.2}
$$

The platform stage curve can be represented by the following equation: 
TABLE 3: Mechanical parameters of polyurethane resin.

\begin{tabular}{lcc}
\hline Density $\rho^{\prime}\left(\mathrm{kg} / \mathrm{m}^{3}\right)$ & Elasticity moduli $E^{\prime}(\mathrm{MPa})$ & Yield strength $\sigma_{\mathrm{d} s}(\mathrm{MPa})$ \\
\hline 1200 & 1600 & 127 \\
\hline
\end{tabular}

TABLE 4: Elasticity moduli calculation results.

\begin{tabular}{|c|c|c|c|c|}
\hline \multirow{2}{*}{ Density $\rho\left(\mathrm{g} / \mathrm{cm}^{3}\right)$} & \multirow{2}{*}{ Relative density } & \multicolumn{3}{|c|}{ Elasticity moduli $E(\mathrm{MPa})$} \\
\hline & & Theoretical value & Test value & Error \\
\hline 0.09 & 0.0750 & 17.29 & 17.65 & 2.04 \\
\hline 0.24 & 0.2000 & 85.63 & 89.73 & 4.57 \\
\hline 0.35 & 0.2833 & 177.81 & 175.95 & 1.06 \\
\hline
\end{tabular}

TABLE 5: Yield strength calculation results.

\begin{tabular}{|c|c|c|c|c|}
\hline \multirow{2}{*}{ Density $\rho\left(\mathrm{g} / \mathrm{cm}^{3}\right)$} & \multirow{2}{*}{ Relative density } & \multicolumn{3}{|c|}{ Yield strengths $\sigma_{t}(\mathrm{MPa})$} \\
\hline & & Theoretical value & Test value & Error $(\%)$ \\
\hline 0.09 & 0.0917 & 0.51 & 0.52 & 1.92 \\
\hline 0.24 & 0.2000 & 3.51 & 3.49 & 0.57 \\
\hline 0.35 & 0.2833 & 7.32 & 7.34 & 0.27 \\
\hline
\end{tabular}

$$
\frac{\sigma}{\sigma_{t}}=1
$$

The densification stage curve can be signified by the following equation:

$$
\frac{\sigma}{\sigma_{t}}=\frac{3}{4} \rho^{0.2}(1-\varepsilon)^{-k}
$$

where $k$ is an empirical value for foams. On the basis of the experimental data, $k$ is taken as 0.95 .

\section{Comparison of Calculated Results from Constitutive Model and Compression Experimental Results}

According to the theoretical formula deduced in the previous section and based on the mechanical parameters of low-exotherm polyurethane grouting matrix materials (as listed in Table 3), the characteristic parameters of lowexotherm polyurethane grouting materials possessing various densities at the three stages can be calculated. The elasticity moduli for the elastic stage are listed in Table 4. The yield strengths for the platform stage are listed in Table 5.

Using the theoretical data, the stress-strain curves for densities of $0.09,0.24$, and $0.35 \mathrm{~g} / \mathrm{cm}^{3}$ are plotted, as presented in Figure 13.

According to the comparison between theory and experiment, the constitutive model derived in this paper satisfactorily simulates the stress-strain curves of low-exotherm polyurethane grouting materials possessing various densities. The errors are within $5 \%$.

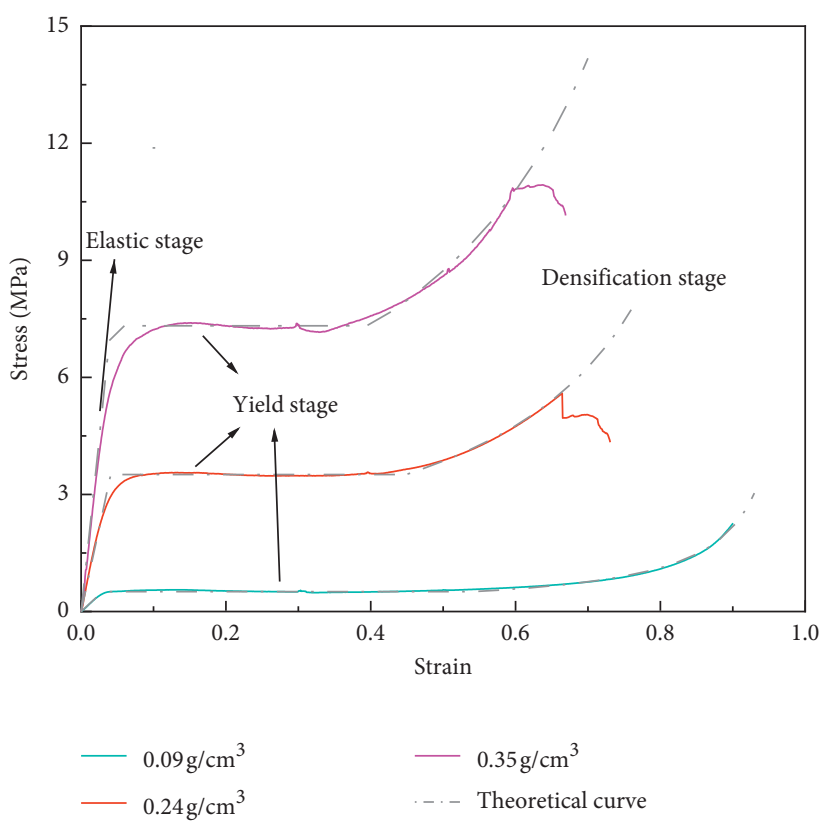

Figure 13: Theoretical and measured curve diagram of low-exotherm modified polyurethane grouting materials.

\section{Prediction of Compression Characteristics Based on Constitutive Model}

Theoretical predictions are also performed for the $0.11 \mathrm{~g} / \mathrm{cm}^{3}$ specimen, which is not used in the data fitting for the constitutive equations, and the predicted and measured curves are shown in Figure 14. The mechanical parameters are listed in Table 6 .

According to the comparison between the predicted and measured results, the constitutive model accurately predicts 


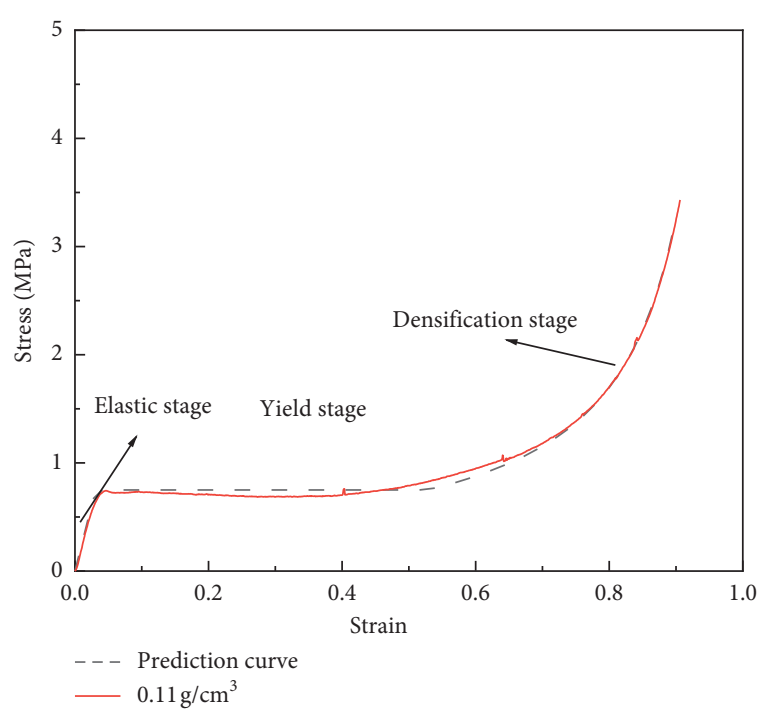

FIGURE 14: $0.11 \mathrm{~g} / \mathrm{cm}^{3}$ prediction and test stress-strain curve.

TABle 6: The mechanical parameters of $0.11 \mathrm{~g} / \mathrm{cm}^{3}$ specimen.

\begin{tabular}{lcccc}
\hline $\begin{array}{l}\text { Elasticity moduli } \\
(\mathrm{MPa})\end{array}$ & $\begin{array}{c}\text { The curve } \\
\text { intersection } \\
\text { point of } \\
\text { elastic stage } \\
\text { and } \\
\text { Theoretical } \\
\text { stage }\end{array}$ & $\begin{array}{c}\text { Yield strengths } \\
(\mathrm{MPa})\end{array}$ & $\begin{array}{c}\text { The curve } \\
\text { intersection } \\
\text { point of } \\
\text { platform } \\
\text { stage and }\end{array}$ \\
\hline 24.62 & Test & $\begin{array}{c}\text { Theoretical } \\
\text { densification } \\
\text { stage }\end{array}$ \\
\hline
\end{tabular}

the mechanical parameters and stress-strain curves of lowexotherm polyurethane grouting materials, thereby providing a valuable reference for various engineering applications such as repair and reinforcement.

\section{Conclusions}

In this study, the modified polyurethane grouting material is modified by changing the catalyst, blowing agent, and reaction scheme to reduce the heat released during the reaction. The unconfined uniaxial compression experiments are conducted for low-exotherm modified polyurethane grouting material specimens possessing various densities, and the stress-strain characteristics and failure responses of the materials are tested. According to the experimental results, the specimens can be divided into three stages from the beginning of loading to the failure of the specimen, namely, the linear elasticity stage, platform stage, and densification stage. The elasticity stage generally lasts until the strain reaches 0.05 , and in this stage, the deformation is recoverable after unloading. When the strain is greater than 0.05 , the specimen undergoes a transition from elastic deformation to plastic deformation, and the stress changes little or is unchanged with increasing strain, which is the platform stage. The duration of the platform stage decreases with increasing density, and for low-density specimens, the platform stage persists until the strain reaches 0.5 . At the end of the platform stage, the stress increases rapidly with increasing strain, and the slope approaches the elasticity modulus of the matrix.

According to the experimental results obtained for the specimens of various densities and microscopic characteristics, the constitutive model for predicting the stress-strain curves of low-exotherm modified polyurethane grouting materials possessing various densities during the three stages is established. The constitutive model settled in this work is used to effectively simulate the stress-strain curves for several densities $\left(0.09,0.24\right.$, and $\left.0.35 \mathrm{~g} / \mathrm{cm}^{3}\right)$.

The predicted stress-strain curve for a specimen with a density of $0.11 \mathrm{~g} / \mathrm{cm}^{3}$, which is not used in the data fitting for the constitutive model, is in good agreement with the experimental curve. The obtained results are expected to prove useful for predicting other mechanical properties of lowexotherm modified polyurethane grouting materials and improving grouting technology for maintaining infrastructure in seasonal or permafrost regions.

\section{Data Availability}

The data used to support the findings of this study are included within the article.

\section{Conflicts of Interest}

The authors declare that they have no conflicts of interest.

\section{Acknowledgments}

The authors acknowledge the support received from the National Key Research and Development Plan (Grant no. 2018YFB1600200), National Natural Science Foundation of China (Grant nos. 51878624 and 51878622), Major Scientific and Technological Special Project in Henan (Grant no. 181100310400), Innovation Team Development Plan of Ministry of Education for financial support (Grant no. IRT15R60), Program for Innovative Research Team (in Science and Technology) at the University of Henan Province (Grant no. 18IRTSTHN007), Program for Science and Technology Innovation Talents in Universities of Henan Province (Grant no. 19HASTIT041), Key Research Projects of Higher Education in Henan Province (Grant no. 18A580001), Henan Province Science Fund for Distinguished Youth Scholars (Grant no. 02300410354), and Cooperation Projects (Grant no. 2017-ZJKJ-PTJS03).

\section{References}

[1] M. Cao, C. Wang, R. Xia et al., "Preparation and performance of the modified high-strength/high-modulus polyvinyl alcohol fiber/polyurethane grouting materials," Construction and Building Materials, vol. 168, pp. 482-489, 2018.

[2] H. Liu, F. Wang, M. Shi, and W. Tian, "Mechanical behavior of polyurethane polymer materials under triaxial cyclic loading: a particle flow code approach," Journal of Wuhan University of Technology-Mater. Sci. Ed, vol. 33, no. 4, pp. 980-986, 2018.

[3] X. Gao, W. Huang, Y. Wei, and Y. Zhong, "Experiment and modeling for compressive strength of polyurethane grout 
materials," Acta Materiae Compositae Sinica, vol. 34, no. 2, pp. 438-445, 2017.

[4] J. V. Mane, S. Chandra, S. Sharma et al., "Mechanical property evaluation of polyurethane foam under quasi-static and dynamic strain rates-an experimental study," Procedia Engineering, vol. 173, pp. 726-731, 2017.

[5] W. Chen, F. Lu, and N. Winfree, "High-strain-rate compressive behavior of a rigid polyurethane foam with various densities," Experimental Mechanics, vol. 42, no. 1, pp. 65-73, 2002.

[6] C. Y. Song and D. Y. Cho, "Cryogenic compressive strength and thermal deformation of reinforced polyurethane foam material for membrane type LNG carrier," Key Engineering Materials, vol. 773, pp. 30-39, 2018.

[7] F. Cadamagnani, S. Frontoni, M. Bianchi, and F. Scarpa, "Compressive uniaxial properties of auxetic open cell PU based foams," Physica Status Solidi (B), vol. 246, no. 9, pp. 2118-2123, 2009.

[8] E. Linul, L. Marsavina, T. Voiconi, and T. Sadowski, "Study of factors influencing the mechanical properties of polyurethane foams under dynamic compression," in Proceedings of the International Symposium on Dynamic Deformation and Fracture of Advanced Materials D2FAM 2013, Loughborough, UK, September 2013.

[9] J. T. Fan, J. Weerheijm, and L. J. Sluys, "High-strain-rate tensile mechanical response of a polyurethane elastomeric material," Polymer, vol. 65, pp. 72-80, 2015.

[10] Y. Nie, H. Liao, and W. W. Chen, "Cyclic tensile response of a pre-tensioned polyurethane," Mechanics of Time-Dependent Materials, vol. 22, no. 3, pp. 1-13, 2018.

[11] E. A. Pieczyska, W. K. Nowacki, H. Tobushi, and S. Hayashi, "Thermomechanical properties of shape memory polymer subjected to tension in various conditions," Quantitative Infrared Thermography Journal, vol. 6, no. 2, pp. 189-205, 2009.

[12] C. Yonghan, D. K. Nguyen, and B. C. Chun, "Lateral flexible linking of polyurethane copolymer and the effect on shape recovery and tensile mechanical properties," Polymer Engineering and Science, vol. 50, no. 12, 2010.

[13] X. Gao, Y. Wei, F. Wang, and Y. Zhong, "Fatigue resistant and microstructure evolution of polyurethane grout materials under uniaxial compression," Acta Materiae Compositae Sinica, vol. 34, no. 3, pp. 550-556, 2017.

[14] A. Bezazi and F. Scarpa, "Mechanical behaviour of conventional and negative Poisson's ratio thermoplastic polyurethane foams under compressive cyclic loading," International Journal of Fatigue, vol. 29, no. 5, pp. 922-930, 2007.

[15] A. Andersson, S. Lundmark, A. Magnusson, and F. H. J. Maurer, "Shear behavior of flexible polyurethane foams under uniaxial compression," Journal of Applied Polymer Science, vol. 111, no. 5, pp. 2290-2298, 2009.

[16] F. M. Wang, M. S. Shi, H. J. Li, and Y. H. Zhong, "Experimental study on the anti-permeability properties of polymer grouting materials," Advanced Materials Research, vol. 284-286, pp. 1952-1955, 2011.

[17] Y. J. Yu, K. Hearon, T. S. Wilson, and D. J. Maitland, "The effect of moisture absorption on the physical properties of polyurethane shape memory polymer foams," Smart Materials and Structures, vol. 20, no. 8, Article ID 085010, 2011.

[18] L. Marsavina, T. Sadowski, M. Kneć, and R. Negru, "Nonlinear behaviour of foams under static and impact three point bending," International Journal of Non-Linear Mechanics, vol. 45, no. 10 , pp. $969-975,2010$.
[19] T. Hisaaki, H. Takahiro, H. Shunichi, and E. Yamada, "Thermomechanical constitutive modeling in shape memory polymer of polyurethane series," Journal of Intelligent Material Systems and Structures, vol. 8, no. 8, pp. 711-718, 1997.

[20] M. Wronski, "A new hypoelastic model of the mechanical behaviour of polyurethane foams," Computational Materials Science, vol. 5, no. 1-3, pp. 271-276, 1996.

[21] Q. Zhang, X.-M. Hu, M.-Y. Wu, Y.-Y. Zhao, and C. Yu, "Effects of different catalysts on the structure and properties of polyurethane/water glass grouting materials," Journal of Applied Polymer Science, vol. 135, no. 27, Article ID 46460, 2018.

[22] X. J. Xiang, J. W. Qian, W. Y. Yang, M. H. Fang, and X. Q. Qian, "Synthesis and properties of nanosilica-reinforced polyurethane for grouting," Journal of Applied Polymer Science, vol. 100, no. 6, pp. 4333-4337, 2006.

[23] J. R. W. Leroy, S. H. Goods, D. M. Skala et al., "Formulation for a rigid polyurethane foam having improved impact resistance," Environmental Toxicology \& Chemistry, vol. 34, no. 10, 2002.

[24] L. J. Gibson and M. F. Ashby, Cellular Solids: Structure and properties, Tinghua University Press, Beijing, China, 2003. 